\title{
Ternidens deminutus Revisited: A Review of Human Infections with the False Hookworm
}

\author{
Richard S. Bradbury
}

Slovak Tropical Institute, St. Elizabeth University, 81101 Bratislava, Slovakia; rbradbur76@gmail.com

Received: 18 June 2019; Accepted: 17 July 2019; Published: 18 July 2019

\begin{abstract}
Ternidens deminutus, the false hookworm of humans and non-human primates, represents a truly neglected intestinal helminth infection. The similarity of the eggs of this nematode to those of hookworm both presents a diagnostic challenge and a potential confounder in prevalence surveys of soil transmitted helminths (STH) in regions where T. deminutus is found. The helminth infects non-human primates throughout Africa and Asia, but reports of human infection are almost exclusively found in eastern and southern Africa. Historically, an infection prevalence up to $87 \%$ has been reported from some parts of Zimbabwe. Scarce reports of ternidensiasis have also been made in individuals in Suriname and one from Thailand. Little work has been performed on this parasite since the 1970s and it not known why human infection has not been reported more widely or what the current prevalence in humans from historically endemic areas is. This review serves to revisit this enigmatic parasite and provide detail to a modern audience of parasitologists on its history, clinical presentation, geographic distribution, life cycle, biology, morphology, diagnosis and treatment.
\end{abstract}

Keywords: Ternidens; ternidensiasis; false hookworm; hookworm; soil transmitted helminths; STH; helminth; zoonosis; human; primate

\section{Introduction}

The World Health Organization's (WHO) global target to eliminate morbidity due to soiltransmitted helminths in children by 2020 [1] has resulted in increased interest within the global health community towards the control of STH (the hookworms, Ascaris lumbricoides and Trichuris trichiura). This has included increased activity in the global surveillance of hookworm and other STH prevalence [2]. Surveillance activities in most countries still rely on microscopic detection and identification of eggs. Discrepancies between microscopy and PCR results in some of these surveys have highlighted the existence of human infecting helminths having eggs that may be morphologically confused with those of STH [3]. This has raised the need to revisit the intestinal helminths of humans that are historically known to occur at moderate to high prevalence in some populations and are having eggs morphologically similar to those of other STH.

Ternidens deminutus (the false hookworm) is one such helminth, with infected humans passing eggs that are easily confused with hookworm eggs. Surveys of human intestinal helminths in Zimbabwe during the 1970s revealed a prevalence of this parasite of up to $87 \%$ in some populations [4]. The remarkable similarity of $T$. deminutus eggs to those of hookworms often confounded previous surveys of hookworm prevalence in these regions [5]. Furthermore, T. deminutus infection has not been reported from humans in any surveillance studies for the past 25 years [6], nor in any individual case report since 2005 [7]. In areas where prevalence of this worm was historically high, such as southern Zimbabwe, this is likely due to misidentification of T. deminutus eggs as those of hookworms, rather than elimination of the parasite from these communities. It appears to be time to revisit Ternidens and to inform the current generation of parasitologists and epidemiologists of the existence, diagnosis and treatment of this neglected tropical disease. 
Several countries, regions and cities referred to in this review have changed their names multiple times over the past one hundred years. To avoid confusion for readers, the place names current at the time of writing have been used throughout.

\section{History}

T. deminutus (nematoda: Strongylidae) is an intestinal helminth of primates, including humans, monkeys, gorillas and baboons in Africa and Asia (Table 1). The species was first described by Railliet and Henry (1905) [8] when reviewing two museum specimens taken at autopsy in 1865 by the French naval physician Moniester from the intestine of a patient native to Mozambique (but living on the island of Mayotte) who had died of anemia. Originally incorrectly identified as Ancylostoma duodenale by Moniester, Railliet and Henry differentiated the worms on the basis of morphology and described them as Triodontophorus deminutus [8]. In 1908, Turner found upon autopsy a number of female worms in the large intestine of two patients from Malawi who had died working in the mines of Johannesburg (South Africa). These worms were distinct from the Necator americanus specimens found in the same patient's small intestine, both in their morphology and that the site of infection was the large intestine. Leiper (1908) [9] examined these worms and identified them as T. deminutus [10]. The following year, Railliet and Henry (1909) [11] revised the taxonomy of the family Strongylidae and the name Triodontophorus was suppressed as a synonym for a new genus, Ternidens. Stannus sent a number of worms recovered post-mortem from the intestines of prisoners from Loma, Malawi to Leiper who identified them as T. deminutus, though these particular cases were not reported in the literature until they were communicated by Sandground in 1931 [12].

Infection in primates was first reported by Leiper, in a western lowland gorilla (Gorilla gorilla gorilla) taken from Gabon which died at the London zoological gardens. Between 1906 and 1937, infection was identified in numerous species of monkeys from Africa and Asia, as well as in a baboon (Papio ursinus griseipes) and a chimpanzee (Pan troglodytes versus) [13]. Smith, Fox and White (1908) [14] described a new worm, Globocephalus macaci in a pig-tailed monkey (Macaca nemestrina nemestrina) which died at the Philadelphia zoo, but this worm was considered to be T. deminutus by Sandground [12].

The significance of $T$. deminutus as a human pathogen became more widely recognized following the work of Sandground in Zimbabwe in the late 1920s [12,15]. Sandground first identified a novel and unusual helminth egg in the feces of an American medical missionary working in the Mount Selinda region of that country. He first considered this nematode as possibly belonging to the genera Trichostongylus or Oesophagostomum. However, on receipt of several fecal samples and adult worms taken from people in the immediate vicinity of the mission where the patient worked, the parasites were identified as T. deminutus [15].

In response to this finding, Sandground traveled to Southern Africa and carried out surveys for T. deminutus infection on workers at the City Deep Goldmine in Johannesburg, the Mount Selinda and Chikore regions of south east Zimbabwe, Livingstone in Zambia and the Gogoyo region and Maputo city regions of Mozambique. Based on results from the $\mathrm{NaCl}$ passive flotation technique, Ternidens infection prevalence of over $50 \%$ was reported from some regions, while in others few or no T. deminutus infections were identified. In Johannesburg, 15 of 503 individuals (3\%) were found to be infected with T. deminutus, eleven of whom were from Mozambique, although some patients from the Eastern Cape and Gauteng region of South Africa were also found to be infected [15]. At Mt. Selinda, $112 / 190(59 \%)$ of individuals tested harbored T. deminutus, either alone $(\mathrm{n}=48)$ or in co-infection with hookworms $(n=64)$. At Chikore, 8/12 $(67 \%)$ were infected, while at Gogoyo, 34/124 (27\%) were infected, with all but one being co-infected with hookworms. No T. deminutus infections were found amongst 54 individuals in Livingstone. Of 323 individuals from many parts of Mozambique examined in Maputo, only one was infected with Ternidens [12]. At Mount Selinda, infection intensity of between 21 and one hundred individual worms was identified in some patients following treatment with carbon tetrachloride, terachloroethylene or a combination of these drugs with oil of chemopodium [12]. 
Following Sandground's work, Blackie reported that prevalence of T. deminutus infection was between 5.3\% and 16\% in various parts of Zimbabwe [16], while Van den Berghe (1934) [17] reported a prevalence of $15 \%$ in a survey of people in the Katanga region of the Democratic Republic of Congo. A single case was reported from Zambia by Blackie in 1932 [16] and from Mauritius in 1937 by Webb [18]. Forty-four adult worms were provided to the US Naval Medical School in 1947 by the Central Medical Laboratories in Maputo, Mozambique [13]. Several hookworm surveys in Zimbabwe by Gelfand between 1945 and 1965 failed to detect the parasite, which was later suggested as being possibly due to failure to differentiate the eggs from those of hookworm rather than due to its absence in the populations sampled [5].

Table 1. Reported non-human primate hosts of Ternidens deminutus and their geographic range.

\begin{tabular}{ccc}
\hline Host name & Common name & Region \\
\hline Cercocebus atys & Sooty mangabey & Africa \\
Cercopithecus ascanius schmidti & Red tailed monkey & Africa \\
Cercopithecus campbelli & Campbell's monkey & Africa \\
Cercopithecus cephus & Moustached guenon & Africa \\
Cercopithecus diana & Diana monkey & Africa \\
Cercopithecus mona & Mona monkey & Africa \\
Cercopithecus petaurista & Lesser spot-nosed monkey & Africa \\
Chlorocebus aethiops centralis & Grey monkey & Africa \\
Chlorocebus pygerythrus & Vervet (green) monkey & Africa \\
Gorilla gorilla gorilla & Western Gorilla & Africa \\
Macaca mulatta & Rhesus monkey & South East Asia and India \\
Macaca nemestrina nemestrina & Pig tailed macaque & South East Asia \\
Macaca nigra & Black macaque & South East Asia \\
Macaca radiata & Bonnet monkey & India \\
Macaca fascicularis fascicularis & Crab eating macaque & South East Asia \\
Pan troglodytes versus & Chimpanzee & Africa \\
Papio anubis & Olive baboon & Africa \\
Papio ursinus griseipes & Chacma baboon & Africa \\
Pongo pygmaeus & Bornean orang utan & South East Asia \\
\hline
\end{tabular}

\section{Biology and Life Cycle}

The closest relative to of the genus Ternidens is Oesophagostomum $[19,20]$, another nodular intestinal worm affecting both humans and non-human primates in Africa and Asia. Only two species are currently recognized in the genus; T. deminutus and Ternidens simiae. T. deminutus has been reported in monkeys, baboons and humans in Africa and Asia (Table 1). The average size of T. deminutus adults in humans is larger than that of baboons [21]. T. simiae has been reported once from the gut of a monkey in Sulawesi, Indonesia [22], but could not be confirmed [23]. Genetic variations between T. deminutus from different monkey hosts has raised the possibility that several cryptic species may infect different host primates $[19,20]$.

Infection of the definitive host may occur via oral ingestion of third stage (L3 filariform) larvae [24], which establish parasitism in the large intestine, particularly the colon, but also the cecum, compared to hookworms, which are primarily parasites of the duodenum. These L3 larvae are thought to then enter the intestinal mucosa, form nodules in which they mature to L4 larvae and then re-enter the lumen as adults to mate [12,24]. Based on observations of blood in the intestine of adult worms [21] combined with histochemical and biochemical analysis of the contents of worm guts [25] that adult worms possibly ingest blood. Whether they are true blood suckers or simply ingest blood oozing from lesions that they have created in the intestinal mucosa remains unclear [21].

Infections in human subjects examined by Goldsmid [26] found a mean worm load of $22.7 \pm 5.9$ worms per subject and a mean egg output of $494.4 \pm 158.4$ eggs per gram of feces, with a mean egg production of approximately 3500 and 7000 eggs/worm per day [26]. Eggs are passed with eight stage 
(rarely four stage) morulae in the feces [21]. The female:male ratio in both baboons and humans was 1:6 [26]. Eggs become fully mature 24 to $30 \mathrm{~h}$ after passage and the L1 (rhabditiform larvae) hatch after 48-72 $\mathrm{h}$. The L1 rhabditiform larvae develop into L2 stage after two to three days at $29^{\circ} \mathrm{C}$. Development to L3 filariform larvae at this temperature takes eight to ten days [26]. The L3 larvae of T. deminutus appear to be relatively environmentally resistant. Sandground claimed to have revived larvae following three days of desiccation [12]. Experiments by Goldsmid found that approximately $4 \%$ of L3 larvae survived and recovered motility after $24 \mathrm{~h}$ of desiccation at $14{ }^{\circ} \mathrm{C}$ at $60 \%$ relative humidity. After $24 \mathrm{~h}$ in these desiccated conditions, no larvae survived [26]. The morphology of revived larvae following desiccation was greatly affected, with many losing their sheath, developing vacuoles in the cuticle and internal structures becoming unrecognizable $[12,26]$, and thus the infectivity of such affected larvae is not reliable. Resistance to cold was also observed, with over $60 \%$ of 224 larvae surviving at $5{ }^{\circ} \mathrm{C}$ for ten days. Survival continued for 70 days, though the percentage of viable larvae rapidly declined by this time. No viable larvae were detected at 84 days. Larvae did not survive freezing at $-5^{\circ} \mathrm{C}$ for one hour [26]. As is seen with hookworm infection, the passage of T. deminutus eggs in feces shows a seasonal prevalence, with the highest rates of detection in Zimbabwe being during the Summer months, which are characterized by high temperatures and rainfall [20]. When 301 patients between the ages of $0-2$ and $>65$ years of age were examined, egg output was greatest in patients between the ages of 7 and 35 years [20].

Although a direct life cycle is assumed, the failure of attempts to infect volunteers through ingestion of filariform larvae or by transdermal inoculation $[12,15,16]$ also led to the proposal that an insect intermediate host may be involved in transmission [13,21,27]. Termites were suggested as such a possible host due to their being shared in the diet of both humans and monkeys in areas where human infection is common [28].

T. deminutus is thought to be a zoonosis acquired from non-human primates, although some "spillback" from humans to monkey populations may also occur in some areas [21]. Attempts to infect humans via oral ingestion of larvae cultured from a baboon by Sandground [12] were unsuccessful and some have suggested that humans may be the main host species [12,29]. The possible presence of multiple cryptic species might explain this controversy, with a human specific haplotype of the parasite existing alongside several host-specific non-human primate genotypes. This theory is supported by the analogous presence of several host-specific haplotypes, including a human-specific haplotype, in the genetically similar helminth species Oesophagostomum bifurcum [30]. The average size difference between adults in humans and baboons might support this, though such morphological variation in size between hosts is not uncommon in nematode species. This hypothesis would also explain the almost complete absence of human infections in Asia, despite the parasite being prevalent in non-human primates in the continent.

\section{Geographic Distribution and Prevalence}

Ternidens infections of monkeys, chimpanzees and baboons have been reported throughout sub-Saharan Africa and Asia (Table 1). Infections have thus far not been reported in new world primates. In humans, reports of infection have been almost exclusively from sub-Saharan Africa, with only one case report from Thailand and two from Suriname (Figure 1).

Human T. deminutus infections often occur in high prevalence foci, such as seen in several villages of Zimbabwe. In 1972, Goldsmid, undertook to revisit the work of Sandground [12] on T. deminutus and actively surveyed patients at the Harari Central Hospital in Harare, Zimbabwe. Of 5545 patients examined, $208(3.75 \%)$ harbored infections [5]. Several further surveys in eastern and the central north of Zimbabwe (Bindura, Chiweshe, Burma Valley, Masvingo, Nyanga, Lundi, Maramba, Mount Selinda, Sabi Valley, Harare, Triangle and Mutare) by Goldsmid found a wide range of prevalence, between $0 \%$ and $87 \%$ (mean average 19\%; median 9.2\%), in humans. Of 32 baboons tested in Bikita and Marimba, over $70 \%$ were infected. No human cases were found in Kariba, in the North East Zambezi Valley area of the country [31]. A later survey in the Kadoma region of central Zimbabwe by Goldsmid found 
only $0.7 \%$ of 595 people infected [32]. In these surveys, Goldsmid applied the same $\mathrm{NaCl}$ passive flotation technique as Sandground had used in 1931 [12], with T. deminutus identification based on egg size and any difficult to differentiate eggs cultured by the Harada-Mori technique to allow definitive identification of the L3 larvae [5,31,32].

A survey of 4500 people from the Songea district of Tanzania found T. deminutus (identification based on egg size only, technique not stated) in 105 subjects [33]. In a report of 34 cases of intestinal helminthoma from Entebbe, Uganda in 1972, one case of T. deminutus helminthoma of the ileum was confirmed [34]. Two Ternidens infections, identified based on the morphology of the adult worms passed after treatment, in school children from Zimbabwe were reported in a study of the efficacy of albendazole as a hookworm treatment by Bradley in 1990 [35]. A further survey of people in the Burma Valley region of Zimbabwe in 1993 using quadruplicate Kato Katz examination, and identifying T. deminutus based on egg size alone, identified 5\% as having T. deminutus infection [36].

Only one human T. deminutus case has been reported from Asia. This infection occurred in Thailand in 1983, but was not reported until 2002. A helminth was identified upon histology of an intestinal nodule taken from the colon of a 33 year old Thai female as an immature adult male T. deminutus [7]. In this case, the species identification and differentiation from the clinically and morphologically similar Oesophagostomum species was determined only by the width of the parasite in the histological section (300-500 $\mu \mathrm{m}$; $\max 550 \mu \mathrm{m})$. This larger diameter was the only differentiating feature of this stage of Ternidens from Oesophagostomum in cross section and was the only feature used to make the species identification [7]. However, Oesophagostomum species in section may be up to 700 in diameter [37]. Furthermore, the diameter reported was below that reported for another T. deminutus $(650 \mu \mathrm{m})$ infection in section, admittedly only measured in a single adult female [38]. Without other supporting molecular data, the only human case of human ternidensiasis reported from Asia may represent a misidentification of Oesophagostomum infection.

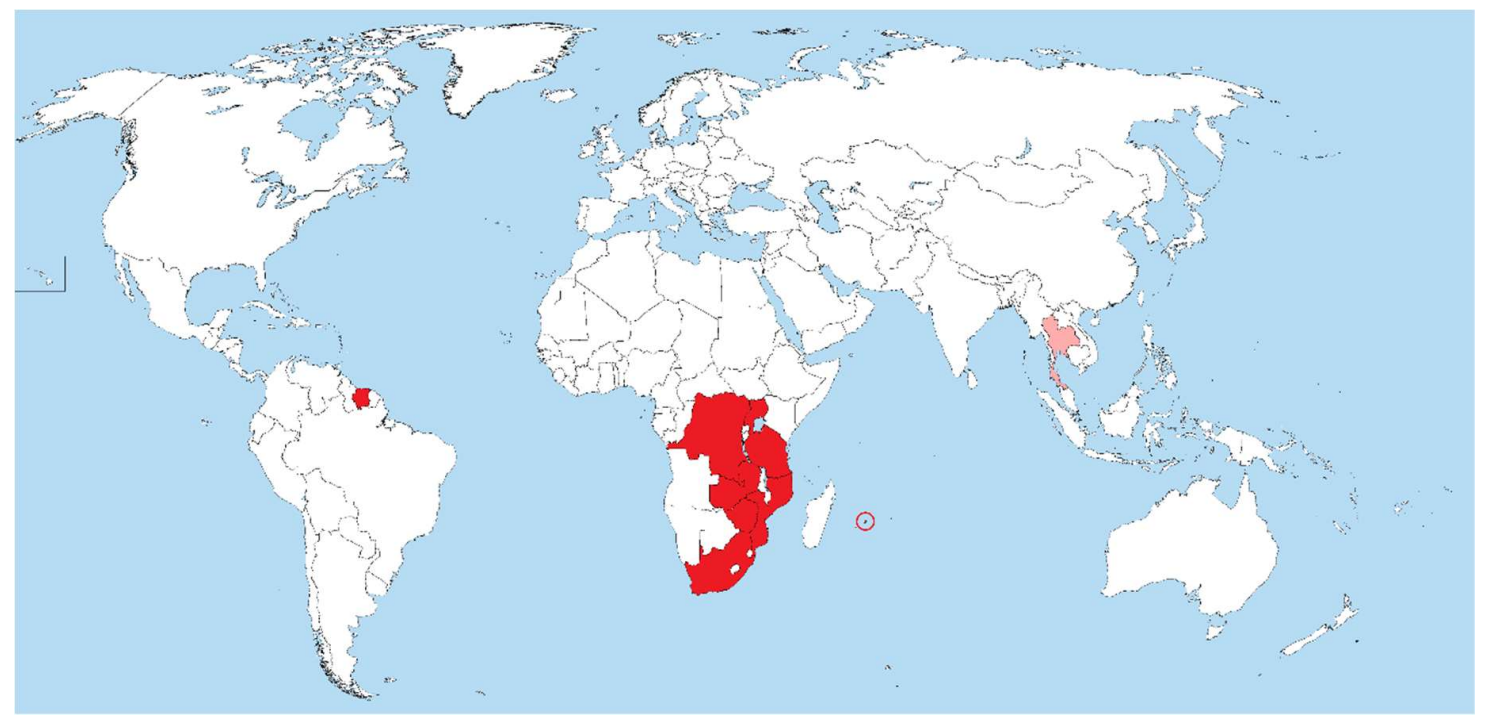

Figure 1. Map of the world showing countries (in red fill) where Ternidens deminutus infection in humans has been confirmed (red circle $=$ Mauritius; pink fill = single case report, possible misidentification of Oesophagostomum infection).

Jozefsoon [6] reported two T. deminutus infections among 431 people belonging to a community of descendants of slaves brought from West Africa and living a traditional lifestyle in the southern interior of Suriname (South America). Identification was based on the morphologic identification of larvae in Harada-Mori culture, with the morphologic approaches described being reliable and the report therefore likely to be accurate. This report was particularly unusual as $T$. deminutus has not been reported from non-human primates on that continent. The people with T. deminutus infection in 
Suriname may be the descendants of people that moved from West Africa, with the remnant worm population still circulating amongst this group [6]. Although it remains occasionally reported in non-human primates [39], no more cases of human Ternidens infection have been reported in the scientific literature since the two Suriname cases in 1994 [6]. Human Ternidens infections have almost certainly not disappeared since this time, rather, it seems likely that when encountered, they are being misidentified as hookworm or Oesophagostomum.

\section{Morphology}

The thin shelled eggs of $T$. deminutus superficially resemble those of hookworms (Figure 2). Eggs are also distinguished from those of hookworms by their larger size (70-94 $\mathrm{mm} \times 40-60 \mu \mathrm{m})$ [21] and greater ratio of width to length (Figure 3) [12]. Eggs may have between four and 32 morulae, which will further develop into larvae within the egg and hatch.

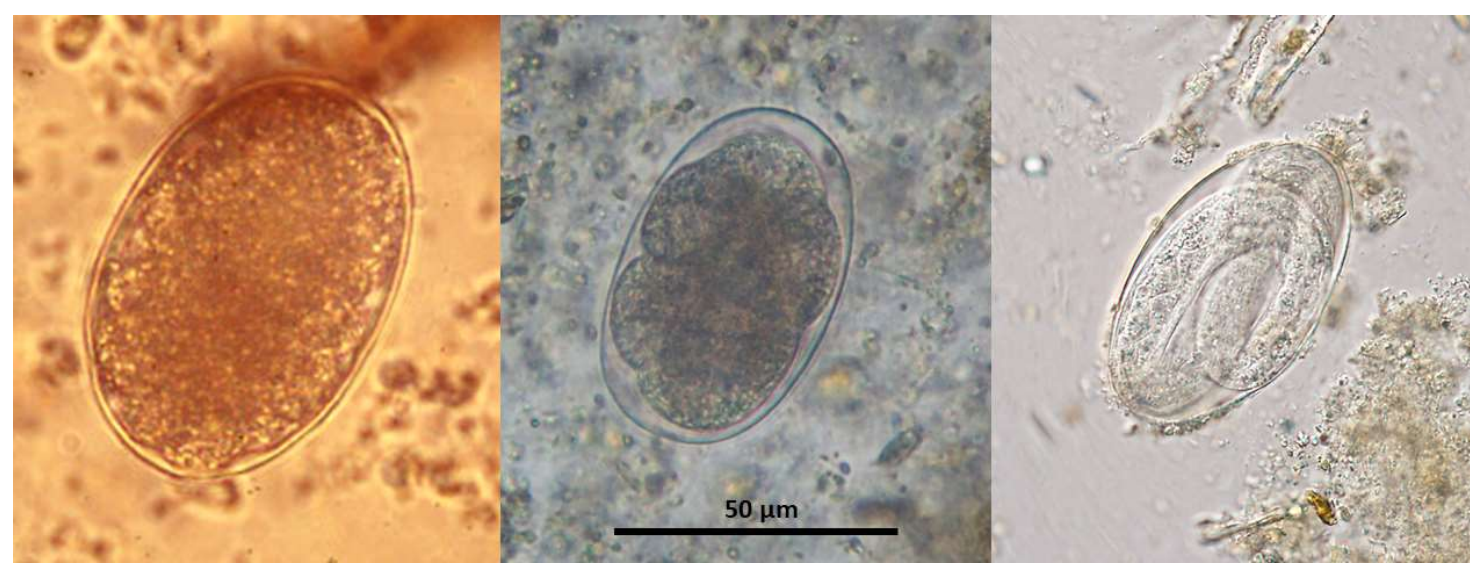

Figure 2. Eggs of T. deminutus (left - photographs courtesy of Emeritus Professor John Goldsmid), Necator americanus (middle - photograph by Richard Bradbury) and Oesophagostomum sp. (with larva developing within - photograph courtesy of CDC DPDx - https://www.cdc.gov/dpdx).

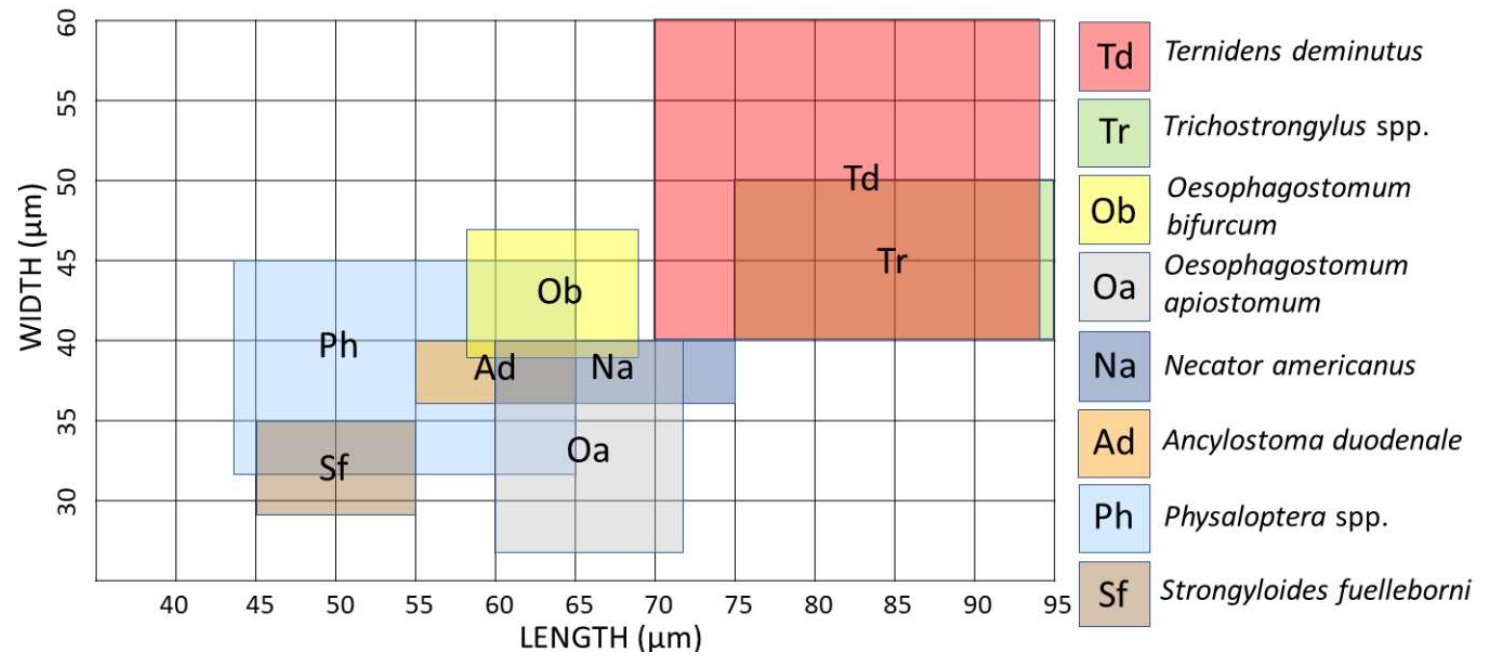

Figure 3. Size range comparison chart of hookworm-like eggs passed in human feces [21,40-42].

The first stage (L1) rhabditiform larvae of T. deminutus measure between 300 and $360 \mu \mathrm{m}$ long by $\sim 20 \mu \mathrm{m}$ at the widest point [12] (Figure 4a). The cylindrical buccal cavity is $10.5 \times 1.5 \mu \mathrm{m}$ in length and breadth and the esophagus approximately $95 \mu \mathrm{m}$ long. A refractile, spindle shaped genital primordium is $11.2 \mu \mathrm{m}$ long. At the distal end, a long flagella-like tail reaches $70 \mu \mathrm{m}$ in length [12]. L2 larvae are longer $(620 \mu \mathrm{m})$ and wider $(32 \mu \mathrm{m})$ with an esophagus $140 \mu \mathrm{m}$ in length (Figure $4 \mathrm{~b})$. While these 
rhabditiform larvae appear similar to those of the hookworms and Strongyloides stercoralis, they may be differentiated by observing the combination of the long buccal cavity, prominent genital primordium, and longer tail.

The filariform (L3) stage larvae of T. deminutus (Figure 4c) are easily distinguished from other "hookworm-like" larvae derived from humans. This life stage measures between 630-730 $\mu \mathrm{m}$ long by 29-35 $\mu \mathrm{m}$ wide and is most distinguished by the palisade "zig-zag" appearance of the gut, shared with larvae of Oesophagostomum. The larval cuticle is distinctly striated and six minute, punctiform, papillae may be found on the head [12]. The head has an indentation at the entrance to the spear shaped remnant buccal cavity [21]. The esophagus measures 150-165 $\mu \mathrm{m}$ in length and is almost uniform in length and width, but for a slight bulge distally. The esophagus to intestine ration is approximately 1:3 [26]. Two elongate sphincter cells divide the esophagus from the intestine and the intestine is composed of at least ten pairs of large triangular cells which provide the palisade appearance of this organ. A genital primordium $15 \mu \mathrm{m}$ long is found hugging the intestinal wall near the middle of the larva. The anus opens between 120-145 $\mu \mathrm{m}$ from the end of the tail [12]. The tail tapers to a fine point and the filamentous end of the sheath extends some distance further, appearing threadlike at the posterior extremity $[6,12]$. This morphologic appearance most closely resembles Oesophagostomum species L3 larvae, but the two may be differentiated by the greater overall length $(702-950 \mu \mathrm{m})$, the " $Y$ " shape of the remnant buccal cavity, the far wider and more prominent, rhabditoid esophageal bulb and the absence of sphincter cells between the esophagus and the intestine in T. deminutus L3 larvae. There is a much shorter distance from anus to the tip of the tail $(45-88 \mu \mathrm{m})$ and the rounded tail of Oesophagostomum [6,40]. Jozefsoon [6] noted if the distance from the tip of the tail to the tip of the sheath is greater than the distance from the anus to the tip of tail, a larva is likely to represent an Oesophagostomum sp. and not T. deminutus.

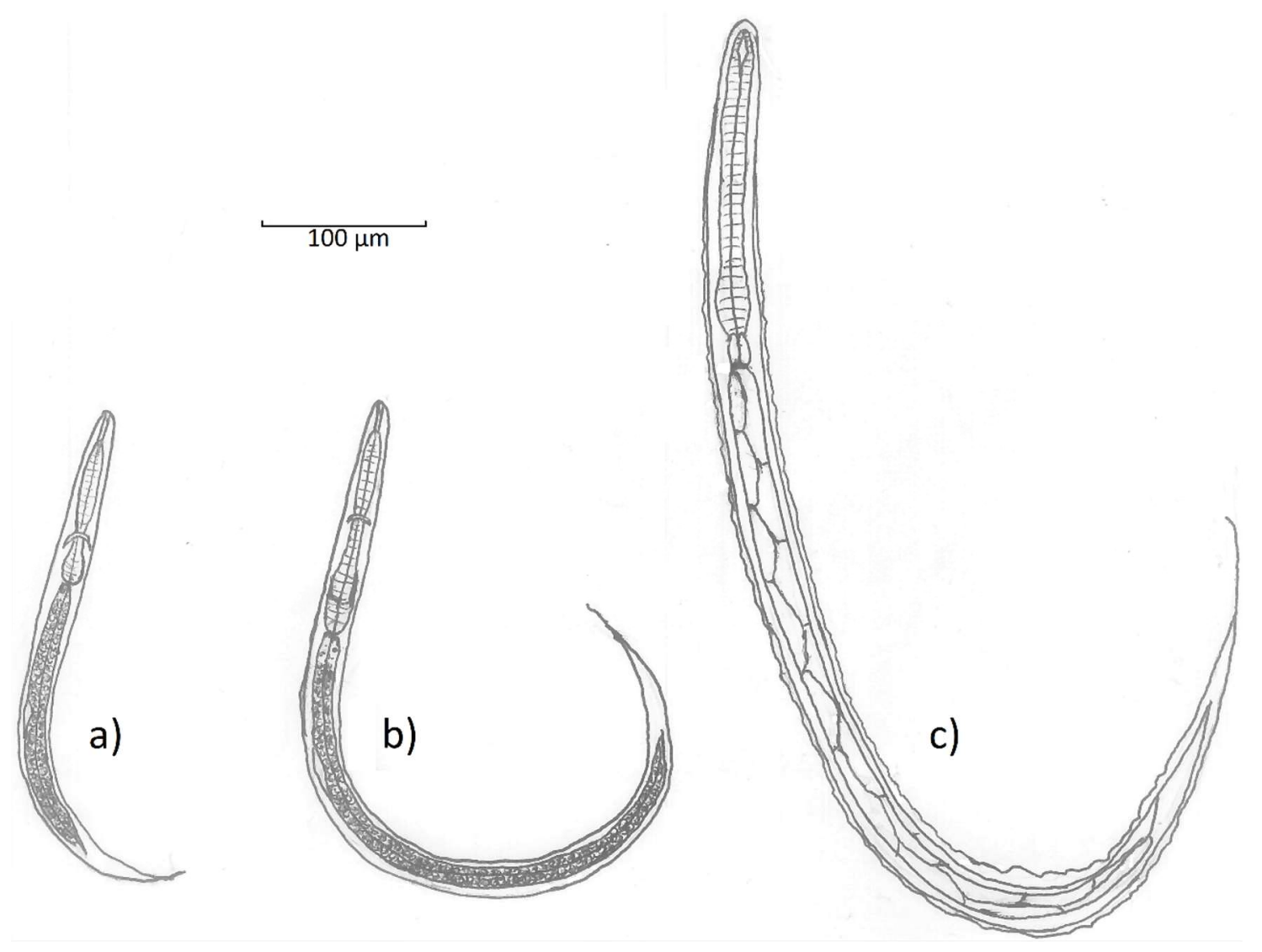

Figure 4. Line drawings showing the morphology of a) rhabditiform (L1) larva; b) rhabditiform (L2) larva and c) filariform (L3) larva of Ternidens deminutus (line drawings by Richard Bradbury). 
Adult female T. deminutus from baboons are 5-12 mm in length (mean $8.60 \pm 0.19 \mathrm{~mm}$ ). Specimens from human hosts measure 9-17 $\mathrm{mm}$ in length (mean $11.56 \pm 0.81 \mathrm{~mm}$ ). Adult males are between $4.5-11 \mathrm{~mm}$ in length (mean $7.96 \pm 0.21 \mathrm{~mm}$ ) from baboons and 6-13 mm in length (mean $9.67 \pm 0.66 \mathrm{~mm}$ ) from human hosts. Specimens from humans appear to be darker in color than those from baboons [23]. Adult Ternidens are straight, unlike the curved appearance of adult hookworms. The cuticle is opaque and a transverse cuticular fold may be seen immediately distal to the buccal capsule. The entire cuticular surface has transverse striations. The large, swollen sub-globose buccal capsule contains an anteriorly facing mouth surrounded by a collar and 22-24 bristles of the corona radia (Figure 5). Four knob shaped sub median papillae and two lateral amphids are present on the anterior surface of the worm. On the base of the buccal capsule are three deep set teeth with two lateral and one central lamellae. The esophagus measures 525-840 (mean 739) $\mu \mathrm{m}$ in human derived worms and 511-837 (mean 727) $\mu \mathrm{m}$ in baboon derived worms. In females, the posterior tapers to a vulva and anus. The distance between the vulva and anus is 372-558 (mean 406) $\mu \mathrm{m}$ in human derived worms and 232-418 (mean 359) $\mu \mathrm{m}$ in baboon derived worms. In male worms, the anterior splays out into a cup shaped bursa consisting of rays encircling two copulatory spicules (Figure 5). A gubernaculum is present. The spicules measure 1116-1441 (mean 1267) $\mu \mathrm{m}$ in human derived worms and 1023-1302 (mean 1178) $\mu \mathrm{m}$ in baboon derived worms [23]. One description of the recovery of a rare deformed adult male Ternidens with bifurcated anterior was made by Lyons and Goldsmid in 1973 [43].

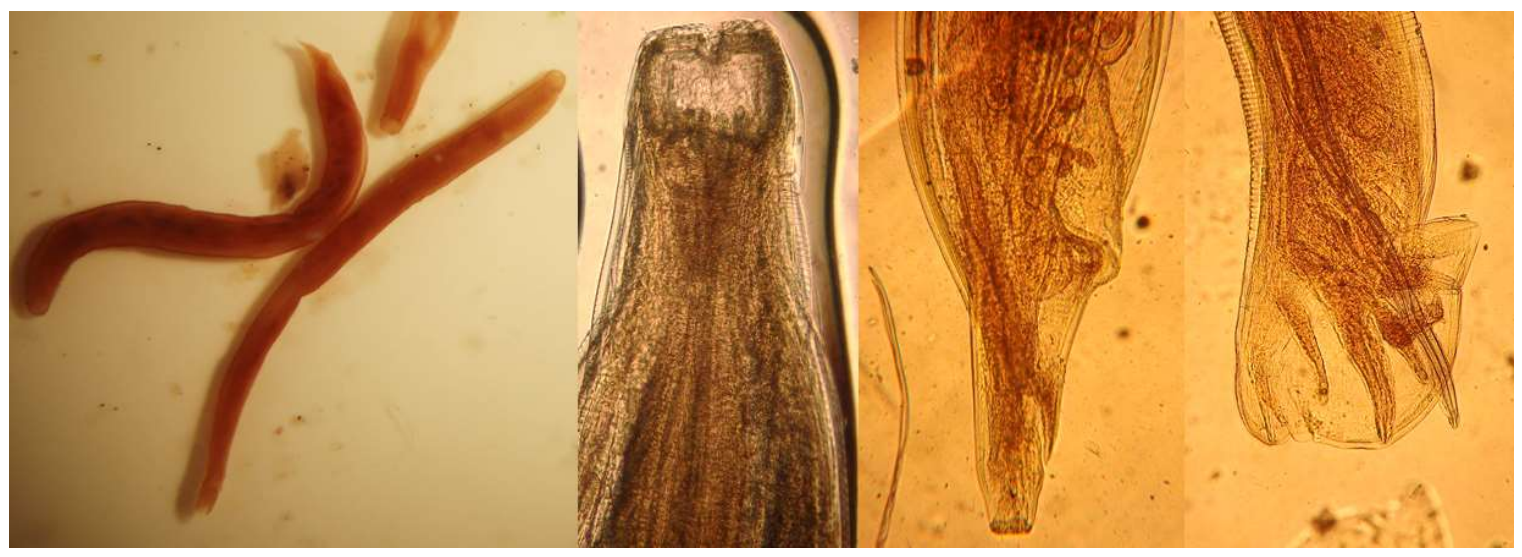

Figure 5. (left to right) adult Ternidens deminutus whole female and male worms from a human; anterior of an adult showing the buccal capsule, posterior of an adult female; posterior of an adult male showing copulatory bursa (photographs by Richard Bradbury).

\section{Clinical Presentation}

Ternidensiasis most commonly presents in a similar manner to oesophagostomiasis [19], with multiple intestinal abscesses, nodules or helminthomas of the large intestine [21]. Adult worms may also be found free in the intestinal lumen attached to the intestinal mucosa [26]. The clinical effects of infection have not been well studied. Infection appears to be asymptomatic in many cases. In some infections with heavy worm loads associated malaise, obstipation [13] and microcytic hypochromic anemia [21] have been reported. Due to the co-infections with other helminths and the poor nutritional condition of the participants involved in many studies, it is difficult to accurately discriminate the contribution of Ternidens infection to anemia as opposed to the effects of other chronic diseases and other parasitic infections.

\section{Laboratory Diagnosis}

The diagnosis of Ternidens has most commonly been undertaken by measurement of size and differentiated from hookworm based on the size of the eggs [21]. Eggs may be found in direct preparations, but recovery is increased by the use of techniques such as saturated salt flotation [12,24], 
Kato Katz [34] and formalin-ethyl acetate sedimentation. Culture of larvae to L3 stage is recommended to allow definitive species identification [6]. Larval culture techniques such as Harada-Mori have been successfully employed to detect and identify Ternidens infections [24]. The Koga agar larval culture technique has not yet been applied the detection of $T$. deminutus but given the previous success of Harada-Mori technique, it appears likely that this method would also be successful. Recovery and identification of the adult worms on purgation or autopsy is the gold standard for diagnosis. No diagnostic PCR for the detection of T. deminutus has been developed thus far.

\section{Treatment}

As much of the work on T. deminutus was performed prior to the advent of benzimidazole derivative and macrocyclic lactone medications, there have been no controlled studies of the efficacy of modern anthelmintics commonly used in mass drug administration campaigns on T. deminutus infection. Historically, oil of chemopodium, carbon tetrachloride or tetrachloethylene were administered, but were ineffective [12,31]. Treatment with phenylene diisothyacyanate resulted in only a $22 \%$ cure rate and bephenium hydroxynapthoate an $87.5 \%$ cure rate [19]. Of the modern drugs available, Thiabendazole yielded a $90.5 \%$ cure rate, while Pyrantel pamoate cured $92 \%$ of cases [27]. One report has described the efficacy of albendazole when administered to two infected school children in Zimbabwe [34]. This suggests that albendazole may be a suitable treatment for T. deminutus infection, but more thorough trials involving albendazole, mebendazole and ivermectin with monitoring for a longer period following treatment would be advisable to comprehensively determine the most effective treatment for infections. In cases where Ternidens is causing a bowel helminthoma, surgical intervention may be indicated [34].

\section{Conclusions}

T. deminutus, the "false hookworm" has long been an enigmatic and often ignored intestinal helminth of humans. Studies into the worm and the disease caused by it have largely been undertaken by two enthusiastic and capable individuals, specifically John Sandground and John Goldsmid, while little attention was paid to this disease by other researchers. Ternidensiasis is a helminth infection of man capable of causing significant pathology in affected patients, including helminthomas and possibly iron deficiency anemia. No doubt the superficial similarity of the eggs to those of hookworm has led to it being misidentified as hookworm in areas of historically high prevalence, where it most likely remains a significant human helminthiasis and may confound the results of future STH prevalence surveys and control efforts. It is hoped that this paper will educate the modern STH and parasite diagnostics community on the existence and importance of Ternidens infection and will encourage further investigation by the community of unusual hookworm-like intestinal helminths into the future.

Funding: This research received no external funding.

Acknowledgments: This paper is dedicated to John Marsden Goldsmid, whose encouragement, mentoring and support were seminal in forming the author's career as a parasitologist.

Conflicts of Interest: The author declares no conflict of interest.

Disclaimer: Richard Bradbury is writing this paper in his personal capacity and in his capacity as a Visiting Professor of Public Health at the Slovak Tropical Institute, St. Elizabeth University, Bratislava, Slovakia.

\section{References}

1. World Health Organization. Intestinal Worms. 2019. Available online: www.who.int/intestinal_worms/ strategy/en (accessed on 28 May 2019).

2. Becker, S.L.; Liwanag, H.J.; Snyder, J.S.; Akogun, O.; Belizario, V., Jr.; Freeman, M.C.; Gyorkos, T.W.; Imtiaz, R.; Keiser, J.; Krolewiecki, A.; et al. Toward the 2020 goal of soil-transmitted helminthiasis control and elimination. PLoS Negl. Trop. Dis. 2018, 12, e0006606. [CrossRef] [PubMed] 
3. Fischer, K.; Gankpala, A.; Gankpala, L.; Bolay, F.K.; Curtis, K.C.; Weil, G.J.; Fischer, P.U. Capillaria Ova and Diagnosis of Trichuris trichiura Infection in Humans by Kato-Katz Smear, Liberia. Emerg. Infect. Dis. 2018, 24, 1551. [CrossRef] [PubMed]

4. Goldsmid, J.M. The African hookworm problem: An overview. In Parasitic Helminths and Zoonoses in Africa; Macpherson, C.N.L., Craig, P.S., Eds.; Unwin Hyman: London, UK, 1991; pp. 101-137.

5. Goldsmid, J.M. Studies on intestinal helminths in African patients at Harari Central Hospital Rhodesia. Trans. R. Soc. Trop. Med. Hyg. 1968, 62, 619-629. [CrossRef]

6. Jozefzoon, L.M.E.; Oostburg, B.F.J. Detection of hookworm and hookworm-like larvae in human fecocultures in Suriname. Am. J. Trop. Med. Hyg. 1994, 51, 501-505. [CrossRef] [PubMed]

7. Hemsrichart, V. Ternidens deminutus infection: First pathological report of a human case in Asia. J. Med. Assoc. Thail. 2005, 88, 1140-1143.

8. Railliet, A.; Henry, A. Le nouveau Sclérostomien (Triodontophorus deminutus nov. sp.) parasite de l'Homme. C. R. Soc. Biol. Paris 1905, 58, 569-571.

9. Leiper, R.T. The occurrence of a rare schlerotome of man in Nyasaland. J. Trop. Med. Hyg. 1908, 2, 1-14.

10. Brumpt, E. Precis de Parasitologie, 4th ed.; Masson et Cie: Paris, France, 1910.

11. Railliet, A.; Henry, A. Sur la classification des Strongylidae. II: Ankylostominae. C. R. Soc. Bull. Paris 1909, 66, 168 .

12. Sandground, J.H. Studies on the life-history of Ternidens deminutus, a nematode parasite of man, with observations on its incidence in certain regions of Southern Africa. Ann. Trop. Med. Parasitol. 1931, 25, 147-184. [CrossRef]

13. Amberson, J.M.; Schwarz, E. Ternidens deminutus Railliet and Henry, a nematode parasite of man and primates. Ann. Trop. Med. Parasitol. 1952, 46, 227-237. [CrossRef]

14. Smith, A.J.; Fox, H.; White, C. Contributions to systematic helminthology. Univ. Pa. Med. Bull. 1908, 20, 283-294.

15. Sandground, J.H. Ternidens deminutus (Railliet \& Henry) as a parasite of man in Southern Rhodesia; together with observations and experimental infection studies on an unidentified nematode parasite of man from this region. Ann. Trop. Med. Parasitol. 1929, 23, 23-31.

16. Blackie, W.K. A helminthological survey of Southern Rhodesia. Indian Med. Gaz. 1932, 67, 475.

17. Van den Berghe, L. L'existence de Ternidens deminutus su Katanga. Ann. Soc. Belge Med. Trop. 1934, 14, 180.

18. Webb, J.L. The helminths of the intestinal canal of man in Mauritius; and a first record of Trichostrongylus axei locally. Parasitology 1937, 29, 469-476. [CrossRef]

19. Metzger, S. Gastrointestinal Helminthic Parasites of Habituated Wild Chimpanzees (Pan Troglodytes verus) in the Taï NP, Côte d'Ivoire-Including Characterization of Cultured Helminth Developmental Stages Using Genetic Markers. Ph.D. Thesis, Freien Universität Berlin, Berlin, Germany, 2014.

20. Schindler, A.R.; De Gruijter, J.M.; Polderman, A.M.; Gasser, R.B. Definition of genetic markers in nuclear ribosomal DNA for a neglected parasite of primates, Ternidens deminutus (Nematoda: Strongylida) Diagnostic and epidemiological implications. Parasitology 2005, 131, 539-546. [CrossRef]

21. Goldsmid, J.M. Ternidens infection. In Parasitic Zoonoses; CRC Press: Boca Raton, FL, USA, 1982; Volume II, pp. 269-288.

22. Yamaguti, S. Parasitic worms mainly from Celebes. Part 10. Nematodes of birds and mammals. Acta Med. Okayama 1954, 9, 1-19.

23. Goldsmid, J.M.; Lyons, N.F. Studies on Ternidens deminutus Railliet \& Henry, 1909 (Nematoda) I. External morphology. J. Helminthol. 1973, 47, 119-126.

24. Goldsmid, J.M. The differentiation of Ternidens deminutus and hookworm ova in human infections. Trans. $R$. Soc. Trop. Med. Hyg. 1968, 62, 109-116. [CrossRef]

25. Goldsmid, J.M. Inorganic elements in adult Ternidens deminutus (Nematoda: Strongylidea: Oesophagostominae) from humans and baboons. J. Helminthol. 1986, 60, 147-148. [CrossRef]

26. Goldsmid, J.M. Studies on the life cycle and biology of Ternidens deminutus (Railliet \& Henry, 1905), (Nematoda: Strongylidae). J. Helminthol. 1971, 45, 341-352.

27. Goldsmid, J.M. The intestinal helminthzoonoses of primates in Rhodesia. Ann. Soc. Belge Med. Trop. 1974, 54, 87-101.

28. Goldsmid, J.M. Ternidens deminutus: A Parasitological Enigma in Rhodesia; Faculty of Medicine Research Lecture Series No. 4; University of Rhodesia: Salisbury, Rhodesia, 1971. 
29. Witenberg, G.G. Nematodiases. In Zoonoses; Van der Hoeden, J., Ed.; Elsevier: Amsterdam, The Netherlands, 1964; pp. 529-601.

30. Gasser, R.B.; De Gruijter, J.M.; Polderman, A.M. Insights into the epidemiology and genetic make-up of Oesophagostomum bifurcum from human and non-human primates using molecular tools. Parasitology 2006, 132, 453-460. [CrossRef]

31. Goldsmid, J.M. Ternidens deminutus (Railliet \& Henry, 1909) and hookworm in Rhodesia and a review of the treatment of human infections with T. deminutus. Cent. Afr. J. Med. 1972, 18 (Suppl. 11), 1-14.

32. Goldsmid, J.M.; Rogers, S.; Parsons, G.S.; Chambers, P.G. The intestinal protozoa and helminths infecting Africans in the Gatooma region of Rhodesia. Cent. Afr. J. Med. 1976, 22, 91-95.

33. Kilala, C.P. Ternidens deminutus infecting man in Southern Tanzania. East. Afr. Med. J. 1971, 48, $636-645$.

34. Anthony, P.P.; McAdam, I.W.J. Helminthic pseudotumours of the bowel: Thirty-four cases of helminthoma. Gut 1972, 13, 8-16. [CrossRef]

35. Bradley, M. Rate of expulsion of Necator americanus and the false hookworm Ternidens deminutus Railliet and Henry 1909 (Nematoda) from humans following albendazole treatment. Trans. R. Soc. Trop. Med. Hyg. 1990, 84, 720. [CrossRef]

36. Bradley, M.; Chandiwana, S.K.; Bundy, D.A.P. The epidemiology and control of hookworm infection in the Burma Valley area of Zimbabwe. Trans. R. Soc. Trop. Med. Hyg. 1993, 87, 145-147. [CrossRef]

37. Guiterez, Y. Diagnostic Pathology of Parasitic Infections with Clinical Correlations, 2nd ed.; Oxford University Press: Oxford, UK, 2000.

38. Myers, W.M. Pathology of Infectious Diseases: Helminthiases; Armed Forces Institute of Pathology: Washington, DC, USA, 2000.

39. Pafčo, B.; Č́́žková, D.; Kreisinger, J.; Hasegawa, H.; Vallo, P.; Shutt, K.; Todd, A.; Petrželková, K.J.; Modrý, D. Metabarcoding analysis of strongylid nematode diversity in two sympatric primate species. Sci. Rep. 2018, 8, 5933. [CrossRef]

40. Bradbury, R.S.; Speare, R. Passage of Meloidogyne eggs in human stool: Forgotten, but not gone. J. Clin. Microbiol. 2015, 53, 1458-1459. [CrossRef]

41. Blotkamp, J.; Krepel, H.P.; Kumar, V.; Baeta, S.; Van't Noordende, J.M.; Polderman, A.M. Observations on the morphology of adults and larval stages of Oesophagostomum sp. isolated from man in northern Togo and Ghana. J. Helminthol. 1993, 67, 49-61. [CrossRef]

42. Goldsmid, J.M. Ternidens deminutus Railliet and Henry (Nematoda): A diagnostic problem in Rhodesia. Cent. Afr. J. Med. 1967, 13, 54-58.

43. Lyons, N.F.; Goldsmid, J.M. Abnormal Ternidens deminutus Railliet and Henry, 1909 (Nematoda) from man in Rhodesia. J. Parasitol. 1973, 59, 219-220. [CrossRef] 